\title{
Detailed Chemical Kinetic Mechanisms for Combustion of Oxygenated Fuels
}

\author{
E.M. Fisher, W.J. Pitz, H.J. Curran, C.K. Westbrook
}

This article was submitted to

$28^{\text {th }}$ International Symposium on Combustion, Edinburgh, Scotland, July 30-August 4, 2000

\section{January 11, 2000}

U.S. Department of Energy

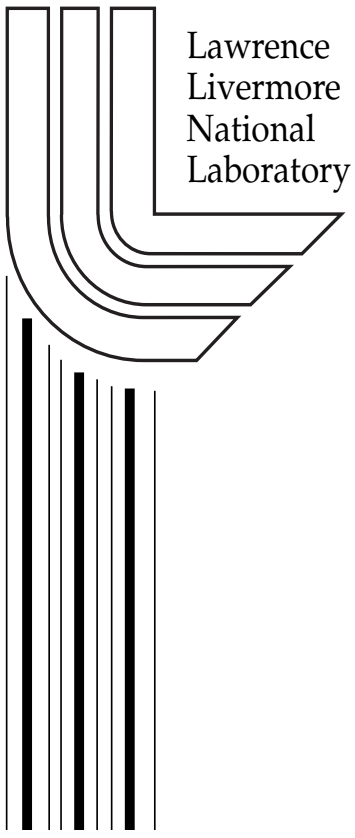




\section{DISCLAIMER}

This document was prepared as an account of work sponsored by an agency of the United States Government. Neither the United States Government nor the University of California nor any of their employees, makes any warranty, express or implied, or assumes any legal liability or responsibility for the accuracy, completeness, or usefulness of any information, apparatus, product, or process disclosed, or represents that its use would not infringe privately owned rights. Reference herein to any specific commercial product, process, or service by trade name, trademark, manufacturer, or otherwise, does not necessarily constitute or imply its endorsement, recommendation, or favoring by the United States Government or the University of California. The views and opinions of authors expressed herein do not necessarily state or reflect those of the United States Government or the University of California, and shall not be used for advertising or product endorsement purposes.

This is a preprint of a paper intended for publication in a journal or proceedings. Since changes may be made before publication, this preprint is made available with the understanding that it will not be cited or reproduced without the permission of the author.

This report has been reproduced

directly from the best available copy.

Available to DOE and DOE contractors from the

Office of Scientific and Technical Information

P.O. Box 62, Oak Ridge, TN 37831

Prices available from (423) 576-8401

http://apollo.osti.gov/bridge/

Available to the public from the

National Technical Information Service

U.S. Department of Commerce

5285 Port Royal Rd.,

Springfield, VA 22161

http://www.ntis.gov/

OR

Lawrence Livermore National Laboratory

Technical Information Department's Digital Library

http://www.llnl.gov/tid/Library.html 


\title{
Detailed Chemical Kinetic Mechanisms for Combustion of Oxygenated Fuels
}

\author{
E.M. Fisher ${ }^{1, *}$, W.J. Pitz ${ }^{2}$, H.J. Curran, ${ }^{2, \#}$, C.K. Westbrook ${ }^{2}$ \\ ${ }^{1}$ Sibley School of Mechanical and Aerospace Engineering \\ Cornell University, Ithaca NY 14853, USA \\ ${ }^{2}$ Chemistry Division, Lawrence Livermore National Laboratories \\ Livermore, CA, 94551, USA \\ \# Permanent address: Chemistry Department, Galway-Mayo Institute of Technology \\ Galway, Ireland
}

* corresponding author

E. M. Fisher

Sibley School of Mechanical and Aerospace Engineering

Upson Hall

Cornell University

Ithaca, NY 14853

USA

email: emf4@cornell.edu

phone: (607)255-8309

fax: (607)255-1222

Colloquium: Reaction Kinetics of Combustion

Word Count:

Figs 1-3: 400 words each

Fig. 4: 200 words

Table 1: 400 words

Text (using Microsoft Word word count): 3700

total: $\mathbf{5 5 0 0}$ words

Preference: oral presentation 


\begin{abstract}
Thermodynamic properties and detailed chemical kinetic models have been developed for the combustion of two oxygenates: methyl butanoate, a model compound for biodiesel fuels, and methyl formate, a related simpler molecule. Bond additivity methods and rules for estimating kinetic parameters were adopted from hydrocarbon combustion and extended. The resulting mechanisms have been tested against the limited combustion data available in the literature, which was obtained at low temperature, subatmospheric conditions in closed vessels, using pressure measurements as the main diagnostic. Some qualitative agreement was obtained, but the experimental data consistently indicated lower overall reactivities than the model, differing by factors of 10 to 50. This discrepancy, which occurs for species with well-established kinetic mechanisms as well as for methyl esters, is tentatively ascribed to the presence of wall reactions in the experiments. The model predicts a region of weak or negative dependence of overall reaction rate on temperature for each methyl ester. Examination of the reaction fluxes provides an explanation of this behavior, involving a temperaturedependent competition between chain-propagating unimolecular decomposition processes and chain-branching processes, similar to that accepted for hydrocarbons. There is an urgent need to obtain more complete experimental data under well-characterized conditions for thorough testing of the model.
\end{abstract}




\section{Introduction.}

Fuels derived from vegetable oils and animal fats offer an alternative to petroleum products for diesel engine combustion. These biodiesel fuels are attractive because of their low sulfur content, which allows the use of a catalyst to remove $\mathrm{NO}_{\mathrm{x}}$ from lean-burn engine exhaust to meet new stringent, governmental emission standards. Biodiesel fuels are also renewable fuels, which have low impact on global warming, and which can help limit dependence on foreign-derived fuel supplies. With oxygen content typically $10 \%$ or greater by mass [1], biodiesel fuels may also provide soot-reduction benefits similar to those observed for other oxygenated diesel fuels and additives [2]. Although oxygenated fuels do not directly reduce $\mathrm{NO}_{\mathrm{x}}$ emissions, their soot reduction capabilities increase flexibility in the choice of engine operating conditions for controlling $\mathrm{NO}_{\mathrm{x}}$ emissions.

For engine applications, biologically derived fatty acids are ordinarily converted into methyl or ethyl esters, to improve physical properties such as viscosity and melting and boiling points. Typical biodiesel fuels consist of mixtures of saturated and unsaturated methyl esters, containing carbon chains 12 or more atoms in length [1]. Numerous engine combustion studies have been performed with these fuels and their constituents [e.g. 3]. However, the few fundamental studies suitable for comparison with chemical kinetic models are restricted to the pyrolysis regime [e.g. 4], as are the only known detailed chemical kinetic models [e.g. 4].

This paper describes the development of a detailed chemical kinetic model for methyl butanoate $\left(\mathrm{C}_{3} \mathrm{H}_{7} \mathrm{C}(=\mathrm{O}) \mathrm{OCH}_{3}\right)$, a surrogate for biodiesel fuels. Although methyl butanoate does not have the high molecular weight of a biodiesel fuel, it has the essential chemical structural features, namely the $\mathrm{RC}(=\mathrm{O}) \mathrm{OCH}_{3}$ structure (where $\mathrm{R}$ is an alkyl or 
alkenyl radical). Little literature information on the thermodynamics and kinetics of $\mathrm{RC}(=\mathrm{O}) \mathrm{OCH}_{3}$ and species derived from it is available. This paper strives to fill in some of these thermodynamic and chemical kinetic gaps. Methyl butanoate was chosen as a surrogate molecule for the larger methyl esters, in order to obtain a reaction mechanism of manageable size. Yet methyl butanoate is large enough to allow fast $\mathrm{RO}_{2}$ isomerization reactions important in the low-temperature chemistry that controls fuel autoignition under conditions found in diesel engines. A model for methyl formate $\left(\mathrm{HC}(=\mathrm{O})-\mathrm{OCH}_{3}\right)$ developed using the same reaction rate rules is presented as well.

Both methyl butanoate and methyl formate are the subject of several lowtemperature oxidation studies performed in small, constant-volume, isothermal static reactors, with $\mathrm{O}_{2}$ as the oxidant [5-8]. Temperatures and initial pressures range from 520 to $740 \mathrm{~K}$ and from 0.13 to $0.53 \mathrm{~atm}$, respectively. Most experiments use rich mixtures, but some experiments are performed with the equivalence ratio as low as 0.65 (methyl butanoate) and 0.1 (methyl formate). Pressure is usually the only measured parameter, with results presented in the form of induction time or maximum rate of pressure rise, taken as representing the maximum reaction rate. Limited major species measurements $[5,7,9]$ are available for methyl formate.

Methyl butanoate $[6,8]$ exhibited a negative temperature coefficient (NTC) region, with a peak in the maximum reaction rate occurring at about $585 \mathrm{~K}$. No NTC behavior was observed for shorter-chain methyl esters including methyl formate [6]. Associated with NTC behavior is the occurrence of cool flames[10]. Cool flame limits, based on observations of luminosity, were reported for methyl butanoate [8,11], while no cool flames were seen for shorter-chain methyl esters [8] including methyl formate [11]. 
More recently Barronet and Brocard [12] summarized cool flame and NTC observations and proposed a criterion for their occurrence based on the availability of relatively fast isomerization pathways for alkyl peroxy radicals derived from the fuel. As several alkyl peroxy radicals derived from methyl butanoate can participate in rapid isomerization reactions, the criterion successfully predicts NTC behavior and cool flames for this compound. However, methyl formate meets the criterion as well, through transfer of an aldehydic hydrogen via a 6-member ring. Barronet and Brocard attribute its lack of NTC and cool flame behavior to its low enthalpy of combustion.

\section{Model Development}

Chemical kinetic calculations were performed with the Senkin code [13], which requires thermodynamic and kinetic data as input. Thermodynamic properties of the methyl esters and their decomposition products were estimated using group additivity [14] as implemented in the THERM code [15] with updated group values [16-18]. Several new bond dissociation groups developed to predict radical properties are listed in Table 1.

The full chemical kinetic mechanism is available from the corresponding author (email: emf4@cornell.edu). For the most part, it follows the rules developed by Curran et al. [20] for n-heptane, as updated an iso-octane study [18]. Because the C-H bond strength for the $\mathrm{C}$ adjacent to the carbonyl in methyl butanoate was very close to the value for tertiary carbon ( 96.2 vs. $96.5 \mathrm{kcal} / \mathrm{mole})$, the rules for tertiary carbon were used for this site. The following classes of reaction were added or changed: (1) Fuel H abstraction by $\mathrm{RO}_{2}$ species formed from the fuel was given half the rate for $\mathrm{H}$ abstraction by $\mathrm{HO}_{2}$. (2) Abstraction of the aldehydic $\mathrm{H}$ in species with two carbonyl groups was 
given rates based on aldehydic $\mathrm{H}$ abstraction. (3) A new approach for $\mathrm{OH}$ and $\mathrm{O}$ addition to olefinic species was based on propene literature. [21-23]. (4) For radical attack on cyclic compounds, Evans-Polyani relations were used for activation energy estimates, representing each $\mathrm{C}-\mathrm{H}$ bond $94 \mathrm{kcal} / \mathrm{mole}$ or weaker with its own set of abstraction reactions. In some cases the product distribution was chosen for convenience rather than to represent products specific to the radical attack site.

The following changes were made in the rules for obtaining rate constants: (1) For isomerization of ester radicals, values of ring strain contributions to activation energy recommended by Benson for alkyl radicals [14] were used. For the $\mathrm{RO}_{2}$ (alkyl peroxy analog) and $\mathrm{O}_{2} \mathrm{QOOH}$ (hydroperoxy alkylperoxy analog) species derived from the esters, the Curran's ring strain values were used [20]. (2) Preexponential factors for isomerization of these three classes of species were obtained respectively by RADICALC [24] calculations of the transition state, by matching rate constants to those of Curran et al. at $700 \mathrm{~K}$, and by adjusting preexponential factors for $\mathrm{RO}_{2}$ isomerization to account for new degeneracy. (3) For QOOH (hydroperoxyalkyl analog) scission to form olefin, carbonyl, and $\mathrm{OH}$ a reverse reaction rate comparable to that for the reverse of alkyl radical beta scission was used. (4) Several specific reaction rates were chosen by analogy with rates for oxygenated species, instead of using the rules developed for alkanes and their derivatives. These reactions fall mainly into the following categories: beta scission, unimolecular fuel decomposition, and RO (alkoxy analog) decomposition.

The methyl butanoate and methyl formate submechanisms were added to an updated version of [18] existing n-heptane mechanism [20]. Reactions involving larger 
hydrocarbons (C4 and higher) were removed to speed calculations. The exclusion of higher hydrocarbons had a minimal effect on calculated results with these ester fuels.

\section{Computational Results: Comparison with Literature Data}

Calculations were performed for comparison with static reactor experimental results [5-8] following the idealized description of experimental conditions provided: namely, combustion was assumed to take place isothermally and at constant volume. Two types of results were compared: the maximum value of the derivative of pressure with respect to time $\left(\mathrm{dP} / \mathrm{dt}_{\max }\right)$, and the induction time, defined as the time at which $\mathrm{dP} / \mathrm{dt}_{\max }$ occurred [6]. $\mathrm{dP} / \mathrm{dt}_{\max }$, which Parsons and Danby [5] indicate is related to the maximum reaction rate, was obtained from calculated pressure by numerical differentiation. In the experiments, pressure was measured with a manometer (probably recorded manually) and thus would not have been able to resolve pressure changes more quickly than every several seconds; computed pressure derivatives did not take into account the manometer response time.

Calculations consistently indicate that combustion is more rapid than is observed experimentally. Fig. 1 shows the calculated and experimental [6] values of $\mathrm{dP} / \mathrm{dt}_{\max }$ for the two methyl esters, as functions of the inverse of temperature. For comparison, Fig. 2 shows the same type of experimental data for propane and propene [25], along with computational results obtained with the hydrocarbon submechanism used in the ester calculations. The present reaction mechanism is based on ones used successfully to model propene oxidation in closed vessels [23] and low-temperature chemistry of propane in flow reactors [26-27]. The experimental apparatus and methods used in the 
various experiments shown in Figs. 1 and 2, performed in the same research group, were very similar. For all four compounds, the calculated $\mathrm{dP} / \mathrm{dt}_{\max }$ was higher than the experimental value, exceeding it by factors of roughly $10,50,10$, and 50 respectively for methyl butanoate, methyl formate, propane, and propene. Features of the experimental curves appear to be displaced 50 to $70 \mathrm{~K}$ higher in temperature in the calculations, possibly indicating that heat release in the experiments caused deviations from the isothermal assumption made in the model. A comparison to a different static reactor experimental data set [8] gives qualitatively similar results: calculated values of $\mathrm{dP} / \mathrm{dt}_{\max }$ show a similar shape to experimental data, but with values 100 times higher.

Discrepancies in the overall speed of reaction, as represented by $\mathrm{dP} / \mathrm{dt}_{\max }$, may be due to errors in the kinetic mechanism or to departures of the experiment from ideal conditions. Because propane and propene, which have relatively well-established kinetic mechanisms, have discrepancies comparable to those for the methyl esters, a problem with the experimental methodology is likely. One plausible explanation is the presence of wall reactions in the experiments, consistent with the reported increase in reactivity with decreasing surface-to-volume ratio in other experiments of the Mulcahy/Parsons research group [28]. Cheaney et al. [29] report that $\mathrm{HO}_{2}$ reacts on the surface of treated silica vessels which as a result of treatment have thin films of silicic, boric, or other acids. They postulate that $\mathrm{HO}_{2}$ donates a proton to the surface. It is likely that other peroxy radicals would behave in a similar manner to $\mathrm{HO}_{2}$. Although vessel surface preparation was not discussed by Parsons et al. [5-7] or Mulcahy [25], closed vessels are often treated with acids prior to their experimental use [e.g. 23]. The magnitude of the effect of peroxy radical losses was investigated computationally by performing additional 
calculations with a rough representation of this type of wall reaction. Reactions converting all peroxy and hydroperoxyperoxy radicals into fictitious non-reactive species were added to the mechanism. Rates for these reactions were chosen to be equal to the collision rate of the species on the wall, multiplied by a constant "efficiency." The vessel volume (0.25 liter) was assumed to be spherical and well-mixed. An efficiency of $1.325 \%$ for all relevant species brought induction time and $\mathrm{dP} / \mathrm{dt}_{\max }$ into agreement with experiment near the middle of the experimental temperature range for methyl butanoate. However, it overcorrected the methyl formate $\mathrm{dP} / \mathrm{dt}_{\max }$ results.

Further indications of overall reactivity are provided in Fig. 3, which shows calculated and observed [6] induction times for the two methyl esters. Comparable experimental data is not available for propane and propene. Two different measures of induction time were applied to the calculated data: (1) the time at which the maximum value of $\mathrm{dP} / \mathrm{dt}$ occurs, and (2) the time at which half the fuel is consumed. These two measures give similar answers at high and low temperatures but differ at intermediate values. The induction time based on the fuel destruction exhibits a smooth dependence on temperature, showing a NTC or near-NTC region in which reactivity has a low or negative dependence on temperature. In contrast, the data based on $\mathrm{dP} / \mathrm{dt}$ shows an unusual dependence on temperature. Instead of a region of NTC behavior as temperature increases, there is an instantaneous shift to a longer induction time. The shift is due to the shape of the pressure histories. Both methyl esters show complex $\mathrm{dP} / \mathrm{dt}$ curves as functions of time, with multiple peaks at certain temperatures. The relative prominence of these peaks changes as temperature increases, leading to an abrupt change in induction time as the location of the maximum value of $\mathrm{dP} / \mathrm{dt}$ shifts from an earlier peak to a later 
one. Because the half width of the first peak is so short (less than a second typically), it is likely that it would not have been observed experimentally with a manometer. The other measure of induction time appears preferable for this reason, and also because it produces NTC results that agree with those seen in Fig. 1. Consistent with the $d P / d t_{\max }$ results, calculated induction times obtained with either measure are factors of 10 to 50 times shorter than those observed experimentally. For both esters, calculated induction times with wall reactions agreed with experiment at some point in the experimental range. However, the temperature dependence of both induction time and $\mathrm{dP} / \mathrm{dt}_{\max }$ was overpredicted considerably.

Qualitative agreement was obtained with experiments [7] on the effect of ester pressure and $\mathrm{O}_{2}$ pressure on reactivity at constant temperature. Fig. 4 shows $d P / d t_{\max }$ calculations along with experimental data that has been normalized to match calculations at one point on each curve. The shape of the curves for both methyl esters is well predicted. Similar agreement was obtained for the effect of ester pressure on induction time based on fuel consumption. For the effect of $\mathrm{O}_{2}$ pressure on $\mathrm{dP} / \mathrm{dt}_{\mathrm{max}}$, agreement in the curve shapes was good for methyl butanoate but poor for methyl formate.

\section{Results: Negative Temperature Coefficient Behavior}

Regions either of negative temperature coefficient (NTC) behavior or of a related weak dependence of $\mathrm{C}$ on temperature ("near-NTC behavior") can be identified by examining either induction time or $\mathrm{dP} / \mathrm{dt}_{\max }$ (indicative of maximum reaction rate). Calculated $\mathrm{dP} / \mathrm{dt}_{\max }$ results indicate that propane, propene, methyl butanoate, and methyl formate have regions of NTC or near-NTC behavior, located at 665-715, 690-765, 640670, and 690-750 K, respectively. The experimental data show similar behavior for 
propane and methyl butanoate, at 50 to $70 \mathrm{~K}$ lower temperatures. Propene data is ambiguous, showing an inflection that can be interpreted as near-NTC behavior. Taking into account the temperature shift between experiment and calculation, methyl formate experiments appear to have been performed at slightly too high a temperature to observe the mild near-NTC region seen in the calculations. Induction times based on fuel destruction show NTC or near-NTC regions consistent with those of Fig. 1, while experimental induction times show no NTC behavior over their temperature range.

Reaction pathway analysis provides an explanation for the methyl butanoate's NTC behavior similar to that accepted for hydrocarbon fuels, e.g. [20]. NTC behavior can be explained by examining the net creation and destruction of radicals in pathways available to the fuel molecule and its derivatives. In this isothermal system, chain branching processes (which increase the radical pool) have a particularly important effect on the overall reaction rate. At two points in the combustion process, there is a competition between (1) unimolecular decomposition pathways leading almost exclusively to chain propagation reactions, and (2) addition to $\mathrm{O}_{2}$, which leads much more frequently to chain branching reactions. The first competition occurs for radicals formed directly by $\mathrm{H}$ abstraction from the fuel. These species can either decompose by beta scission, to produce one radical and one stable molecule, or can add to $\mathrm{O}_{2}$, which in some cases (see below) produces more than one radical. The second competition occurs for the QOOH species formed by isomerization of the $\mathrm{O}_{2}$ addition products of the initial radicals. These species, too, can either decompose unimolecularly, to a radical and either an epoxide-like species or an olefinic species, or can add to $\mathrm{O}_{2}$. The products of this second $\mathrm{O}_{2}$ addition process invariably lead to chain branching processes -- by formation 
either of $\mathrm{OH}$ and a ketohydroperoxide-like species or of $\mathrm{HO}_{2}$ and an olefinic hydroperoxide species. The stable species formed in this way readily decompose to form two radicals.

In each of these competitions, the rate of the unimolecular decomposition process (producing no net radicals) increases more rapidly with increasing temperature than that of the $\mathrm{O}_{2}$ addition process (ultimately producing as many as two net radicals). Thus although all rates increase as temperature increases, higher temperatures favor the chainpropagating processes over the chain branching ones, leading to a net decrease in reactivity over some temperature range. This change can be illustrated for the conditions of Figs. 1 and 3 by considering the fate of the radical formed by abstraction of one of the $\mathrm{H}$ atoms beta to the carbonyl group in methyl butanoate. At $665 \mathrm{~K}$, at the point where half the fuel is consumed, over $99 \%$ of this species reacts with $\mathrm{O}_{2}$. At $765 \mathrm{~K}$, unimolecular decomposition to methyl and an olefinic methyl ester becomes the dominant route, accounting for $75 \%$ of the reaction flux, and at $865 \mathrm{~K}$ the unimolecular decomposition pathway accounts for more than $97 \%$ of the reaction flux. The fate of the isomerization products of the initial $\mathrm{O}_{2}$ addition reaction changes with temperature as well. At $665 \mathrm{~K}$, over $50 \%$ of the flux through these species leads to chain branching, while at $765 \mathrm{~K}$ only $25 \%$ leads to chain branching.

Methyl formate follows a similar pattern, with a shift to chain-propagating unimolecular decomposition reactions when temperatures increase through the NTC region. Its low-temperature branching processes are different from those of methyl butanoate. At $615 \mathrm{~K}$ and $50 \%$ fuel destruction, chain branching proceeds largely through $\mathrm{RO}_{2}$ radicals abstracting $\mathrm{H}$ atoms from other molecules, rather than undergoing internal 
$\mathrm{H}$-atom abstractions via isomerization reactions as discussed for methyl butanoate. Peroxy radicals react with stable species such as $\mathrm{H}_{2} \mathrm{O}_{2}$, forming a radical and a stable hydroperoxide species that decomposes to form radicals, with a net chain branching effect. This hydroperoxide route is observed for methyl butanoate as well, but is less important than the second $\mathrm{O}_{2}$ addition process.

\section{Summary and Conclusions}

Detailed chemical kinetic models for the combustion of methyl butanoate and methyl formate have been developed following rules developed for hydrocarbon combustion. The mechanisms have been tested against the limited combustion data available in the literature, which was obtained at low temperature, subatmospheric conditions in static vessels, using pressure measurements as the main diagnostic. Some qualitative agreement was obtained, but the experimental data consistently indicated lower overall reactivities than the model, differing by factors of 10 to 50 . This discrepancy, which occurs for species with well-established kinetic mechanisms as well as for methyl esters, is tentatively ascribed to the presence of wall reactions in the experiments. The model predicts a region of weak or negative dependence of overall reaction rate on temperature for each methyl ester. Examination of the reaction fluxes provides an explanation of this behavior, involving a temperature-dependent competition between chain-propagating unimolecular decomposition processes and chain-branching processes, similar to that accepted for hydrocarbons. There is an urgent need to obtain more complete and well-characterized experimental data for thorough testing of the model. 


\section{Acknowledgments:}

This work was performed under the auspices of the U.S. Department of Energy by the Lawrence Livermore National Laboratory under contract No. W-7405-ENG-48. The authors thank Prof. J. Bozzelli of the New Jersey Institute of Technology for advice on group additivity values. 


\section{References}

1. Graboski, M.S., and McCormick, R.L., Prog. Energy Combust. Sci. 24:125-164 (1998).

2. Miyamoto, N., Ogawa, H., Nurun, N.M., Obata, K., and Arima, T., "Smokeless, LowNOx, High Thermal Efficiency, and Low Noise Diesel Combustion with Oxygenated Agents as Main Fuel," SAE publication SAE-980506, 1998.

3. Knothe, G., Bagby, M.O., and Ryan, T.W. III, JAOCS. 75(8):1007-1013 (1998).

4. Archambault, D., and Billaud, F., J. Chim. Phys. 96:778-796 (1999).

5. Parsons, B.I. and Danby, C.J., J. Chem. Soc. 1795-1798 (1956).

6. Parsons, B.I. and Hinshelwood, C., J. Chem. Soc. 1799-1803 (1956).

7. Parsons, B.I., J. Chem. Soc. 1804-1809 (1956).

8. Hoare, D.E., Li, T-M., Walsh, A.D., 11th Symposium (International) on Combustion, The Combustion Institute, Pittsburgh, PA, 1967, pp. 879-887.

9. Salooja, K.C., Combust. Flame 10:11-21 (1966).

10. Griffiths, J.F., and Scott, S.K. Progr. Energy Combust. Sci. 13:161-197 (1987).

11. Barnard, J.A. in Comprehensive Chemical Kinetics, C.H. Bamford and C.F.H. Tipper, eds. Elsevier, v.17: 441 (1977).

12. Barronet, F., and Brocard, J.C., Oxidat. Commun. 4(1-4):83-95 (1983).

13. Kee, R.J., Rupley, F.M., and Meeks, E., "CHEMKIN-III: A Fortran Chemical Kinetics Package for the Analysis of Gas-Phase Chemical and Plasma Kinetics," Sandia National Laboratories Report UC-405 SAND96-8216.

14. Benson, S.W., Thermochemical Kinetics, John Wiley and Sons, New York, 1976.

15. Ritter, E.R., and Bozzelli, J.W., Int J. Chem. Kinet. 23: 767 (1991). 
16. Lay, T., Bozzelli, J.W., Dean, A.M., and Ritter, E.R., J. Phys. Chem 99:14514 (1995).

17. Bozzelli, J.W., and Chen, C.-J., New Jersey Institute of Technology, Newark, NJ, personal communication (1999).

18. Curran, H.J., Gaffuri, P., Pitz, W.J., and Westbrook, C.K, "Comprehensive Modeling Study of iso-Octane Oxidation," In preparation, (1999).

19. Melius, C. F., Sandia National Laboratories, Livermore "BAC-MP4 Method Heats of Formation and Free Energies," August 28, 1997.

20. Curran, H.J., Gaffuri, P., Pitz, W.J., and Westbrook, C.K., Combust. Flame 114:149177 (1998).

21. Tsang, W., J. Phys. Chem. Ref. Data 20:221-273 (1991).

22. Stark, M.S., and Waddington, D.J., Internat. J. Chem. Kinet. 27: 123-151 (1995).

23. Wilk, R.D., Cernansky, N.P., and Pitz, W.J., and Westbrook, C.K., Combust. Flame 77: 145 (1989).

24. Bozzelli, J.W., and Ritter, E.R., Chemical and Physical Processes in Combustion, The Combustion Institute, Pittsburgh, PA, 1993, 103:459.

25. Mulcahy, M.F.R., Trans. Faraday Soc. 45:537-541 (1949)

26. Hoffman, J.S., Lee, W., Litzinger, T.A., Santavicca, D.A., and Pitz ,W.J., Combust. Sci. Technol. 77: 95 (1991).

27. Koert, D., Pitz, W.J., Bozzelli, J.W., and Cernansky, N.P. 26th Symposium (International) on Combustion, The Combustion Institute, Pittsburgh, PA, 1996, pp. 633640.

28. Cullis, C.F., Hinshelwood, C., and Mulcahy, M.F.R., Proc. Roy. Soc. A 196:160-171 (1949). 
29. Cheaney, D.E., Davies, D.A., Davis, A., Hoare, D.E., Protheroe, J. and Walsh, A.D., 7th Symposium (International) on Combustion, The Combustion Institute, Pittsburgh, PA, 1969, pp. 183-187. 


\section{FIGURES AND TABLES}

Figure 1. Calculated and experimental [6] values of $\mathrm{dP} / \mathrm{dt}_{\max }$ for isothermal, constantvolume combustion. a) 1:2 mixture of methyl butanoate and $\mathrm{O}_{2}$; initial pressure: 0.395 atm. b) 1:1 mixture of methyl formate and $\mathrm{O}_{2}$; initial pressure: 0.526 atm.

Figure 2. Calculated and experimental [6] values of $\mathrm{dP}^{\mathrm{dt}} \mathrm{t}_{\max }$ for isothermal, constantvolume combustion. 3:25 mixture of a) propane and b) propene with $\mathrm{O}_{2}$; initial pressure: $0.368 \mathrm{~atm}$.

Figure 3. Calculated and experimental [6] values of the induction time a) methyl butanoate; b) methyl formate. Same conditions as Fig.1.

Figure 4. Calculated and normalized experimental [6] values of $\mathrm{dP} / \mathrm{dt}_{\max }$ for isothermal, constant-volume combustion at $\mathrm{O}_{2}$ pressure: 200 torr, T: $653 \mathrm{~K}$.

Table 1. New Group Additivity Values 
Fig 1a

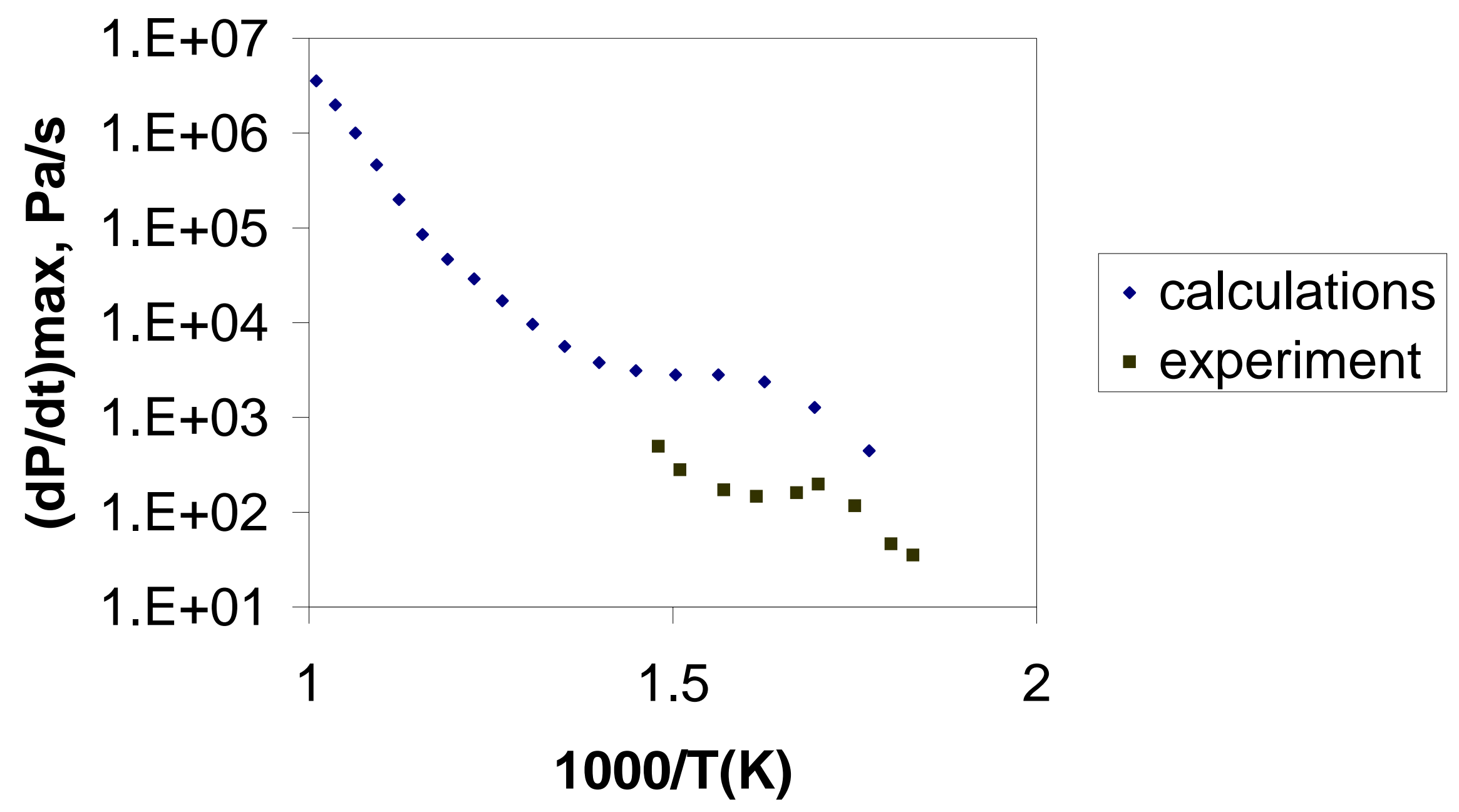


Fig 1b

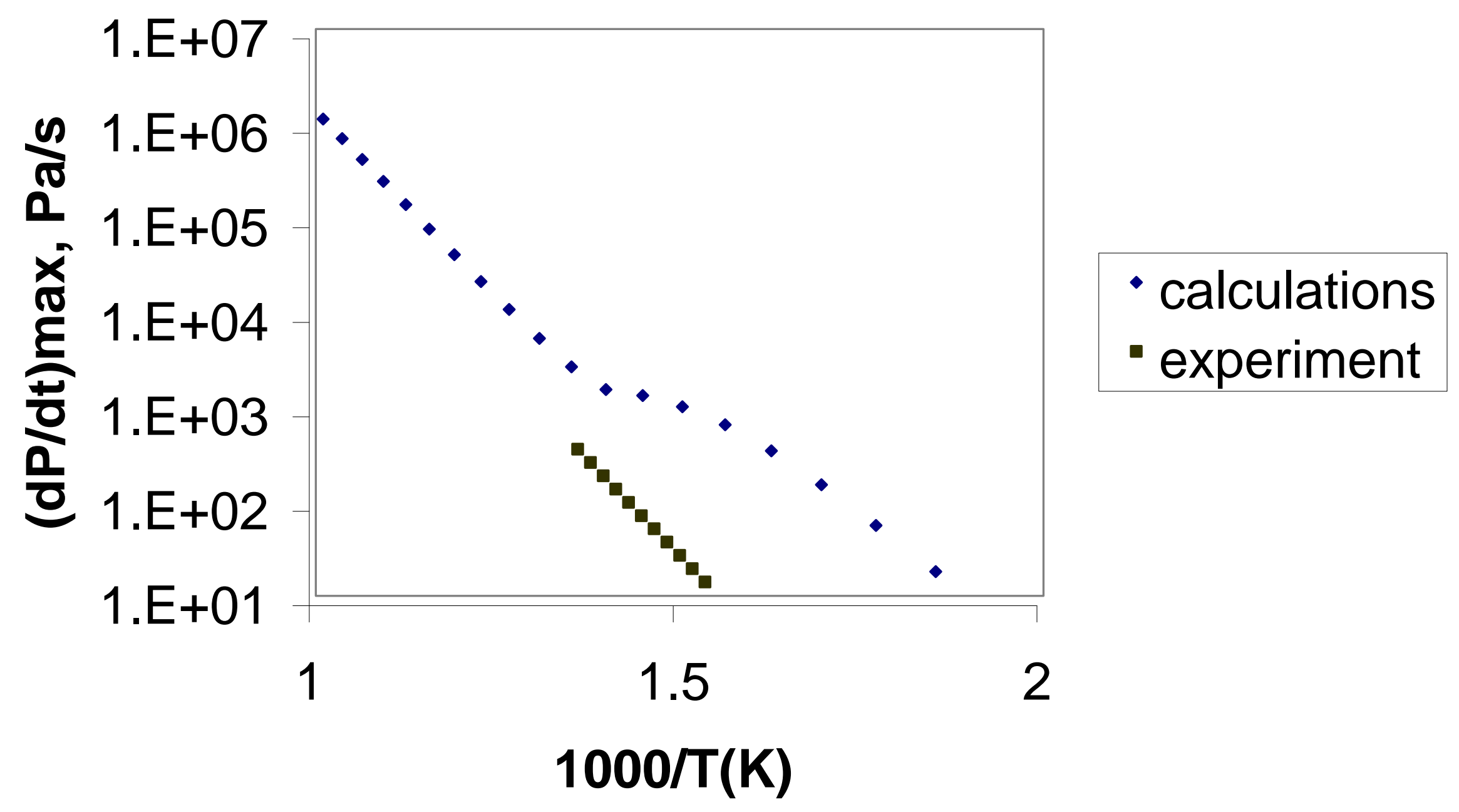


Fig 2a

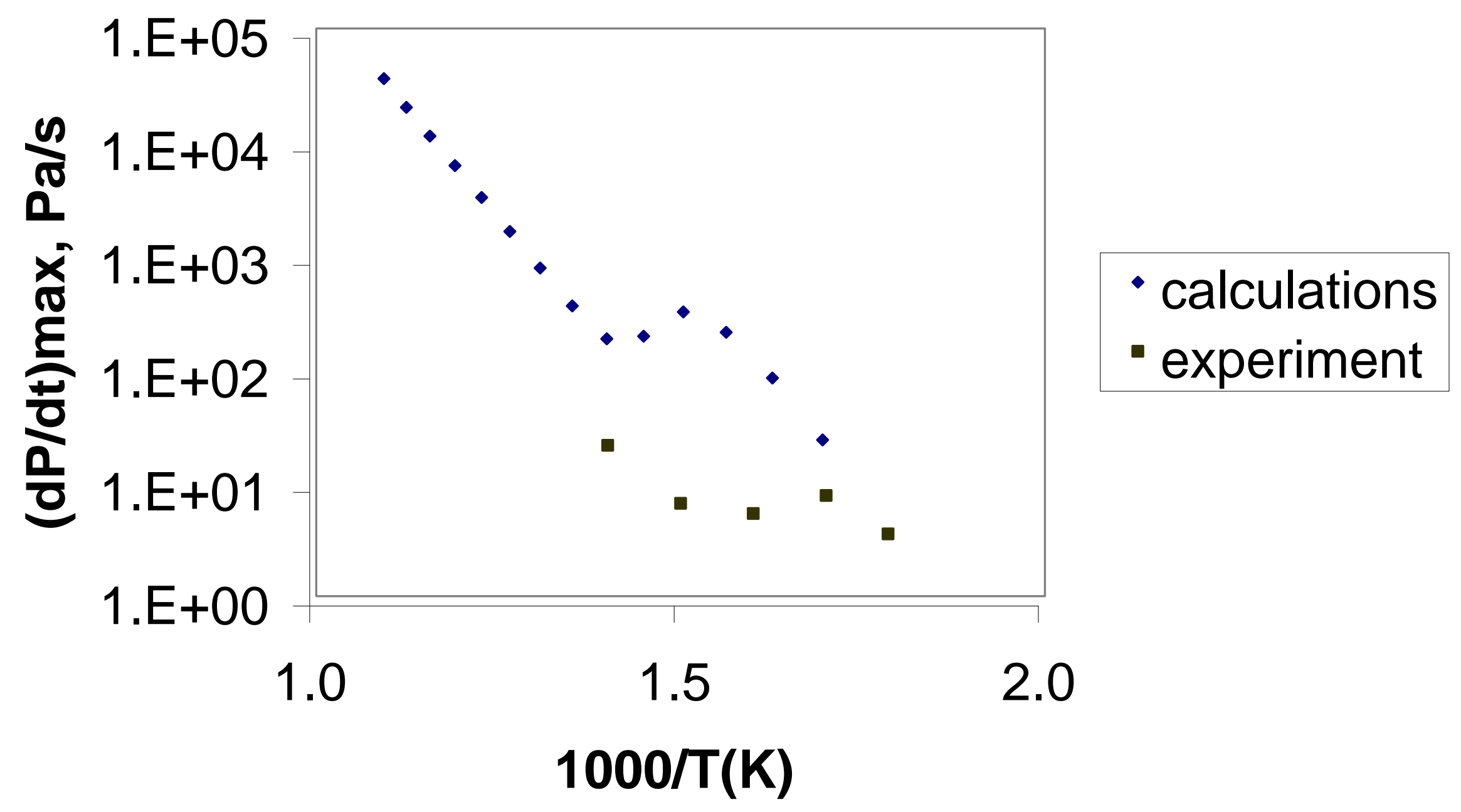


Fig $2 b$

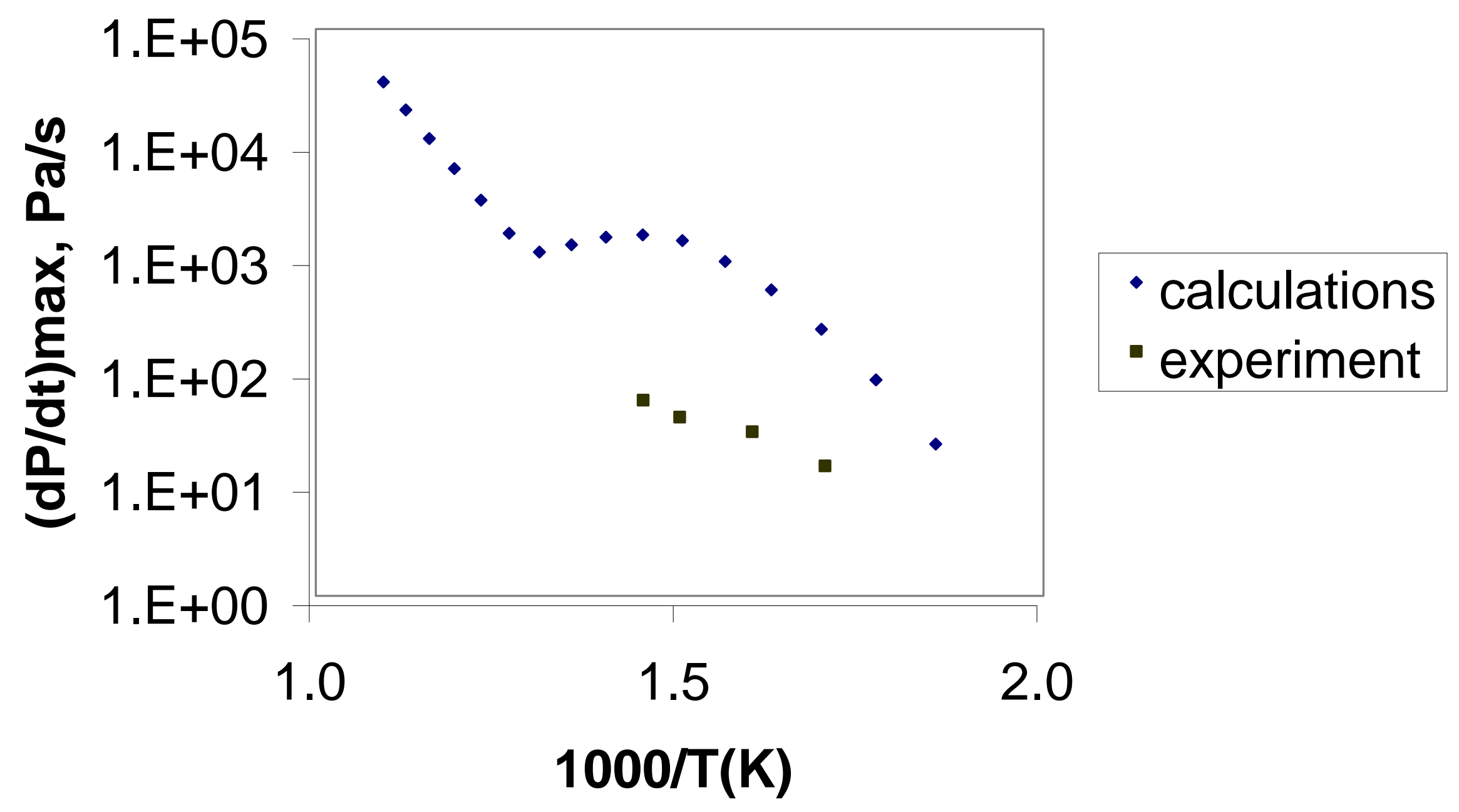


Fig 3a

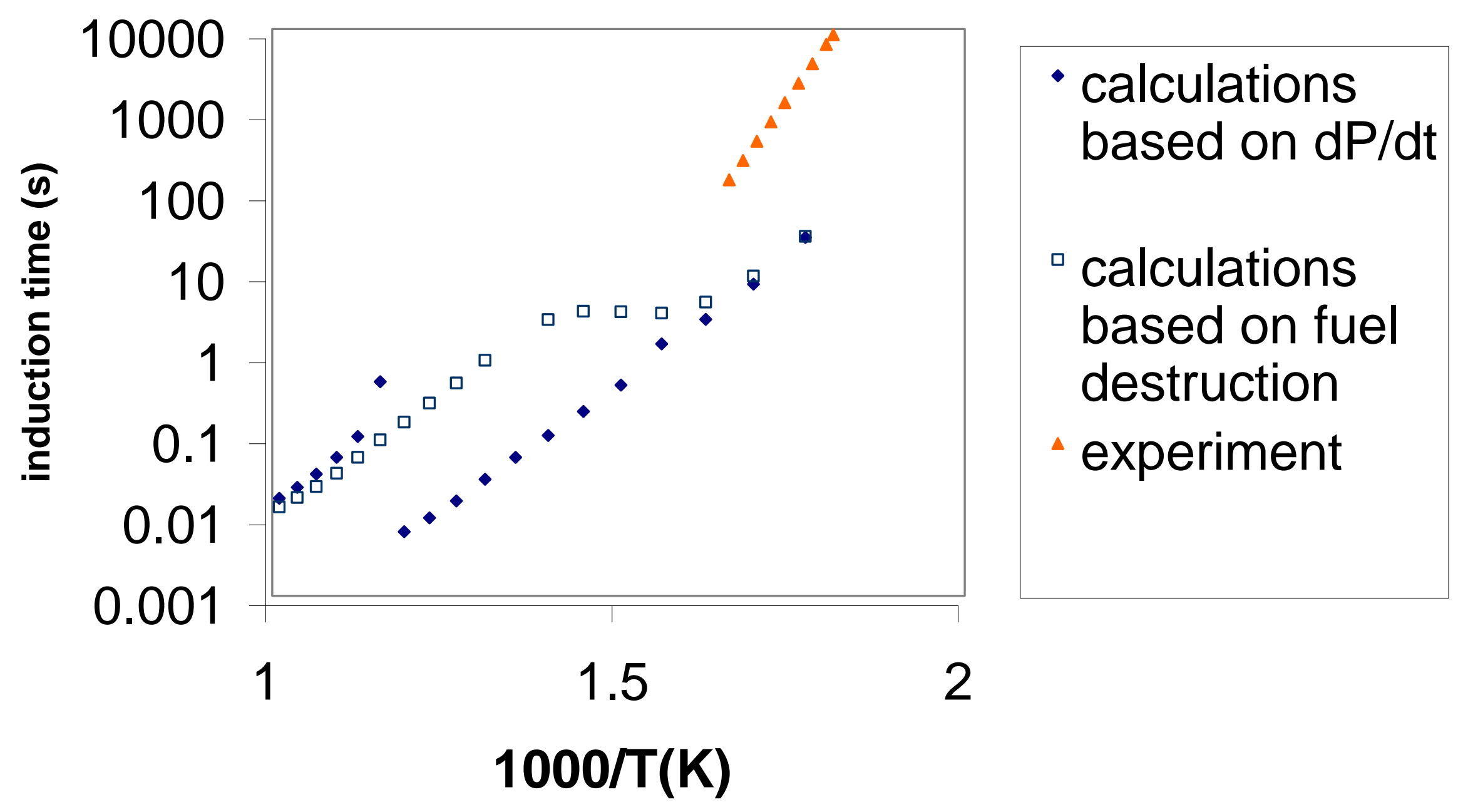


Fig $3 b$

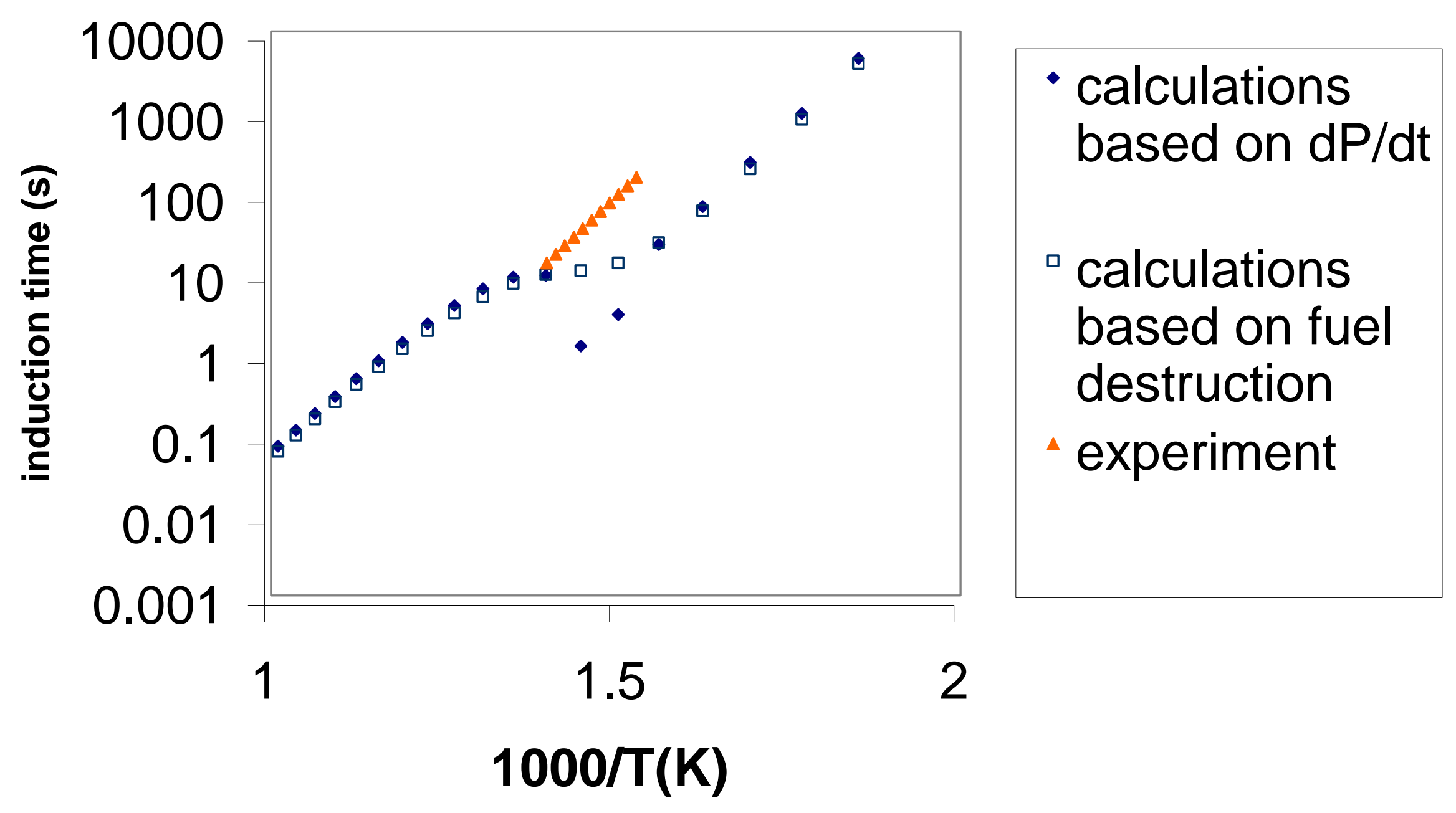


Fig 4

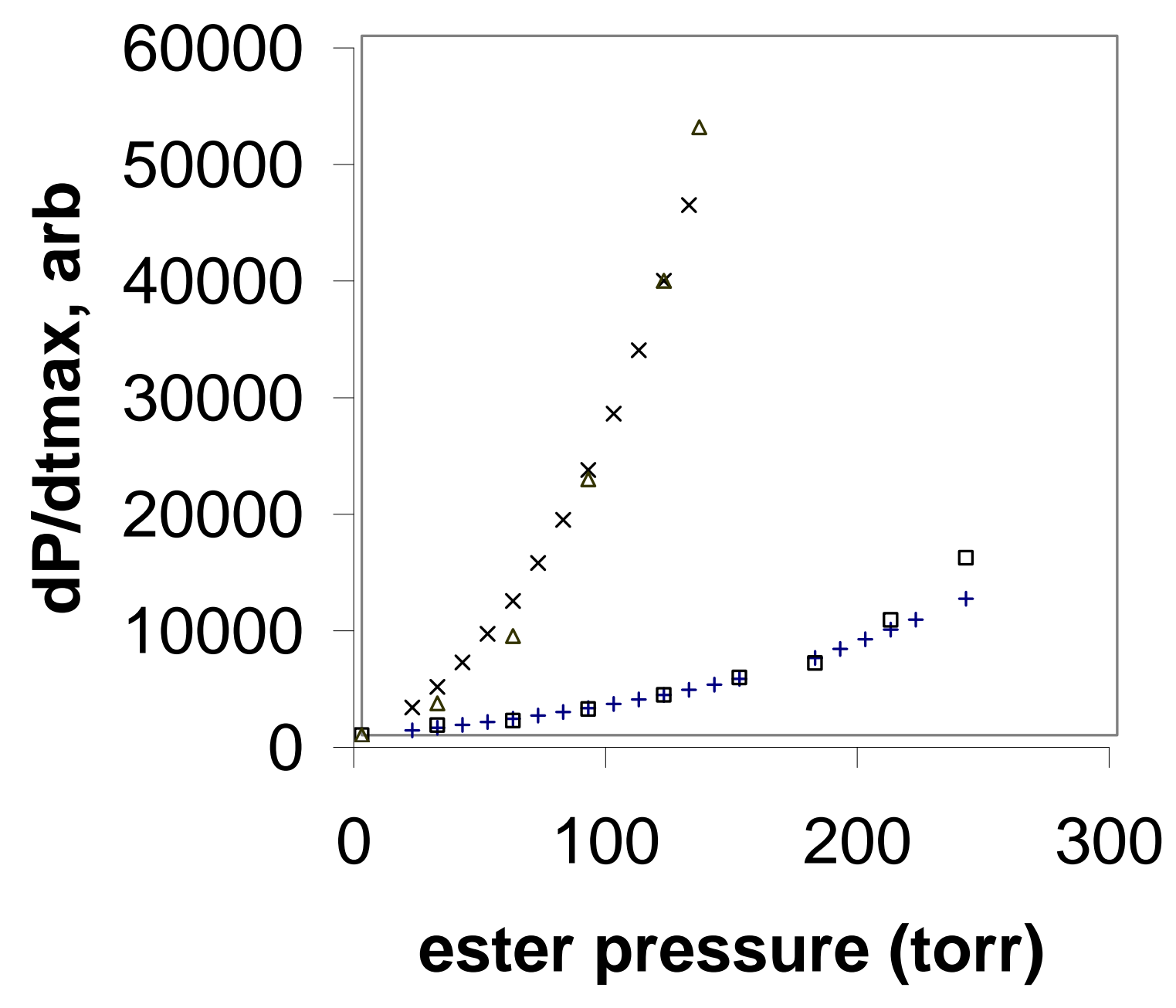

+ calculations, methyl formate

- normalized experiment, methyl formate

* calculations, methyl butanoate

${ }^{\Delta}$ normalized experiment, methyl butanoate 
Table 1.

\begin{tabular}{|l|l|l|l|}
\hline group name & $\begin{array}{l}\Delta \mathrm{H} \\
(\mathrm{kcal} / \mathrm{mole})\end{array}$ & $\begin{array}{l}\Delta \mathrm{S} \\
(\mathrm{cal} /(\text { mole K}))\end{array}$ & basis for values \\
\hline $\mathrm{CH}_{3} \mathrm{OC}()=.\mathrm{O}$ & 98.4 & 0.84 & $\begin{array}{l}\text { comparison of HOCO and HOCHO BAC-MP4 } \\
\text { calculations [19] }\end{array}$ \\
\hline$\cdot \mathrm{CH}_{2} \mathrm{OCHO}$ & 100.35 & 1.73 & $\begin{array}{l}\Delta \mathrm{H} \text { : CBS-Q calculations with group balance } \\
\text { isodesmic reactions [17]; } \Delta \mathrm{S}: . \mathrm{CH}_{2} \mathrm{OR} \text { group [15] }\end{array}$ \\
\hline$\cdot \mathrm{CH}_{2} \mathrm{C}(=\mathrm{O}) \mathrm{OR}$ & 98.8 & -1.31 & $\begin{array}{l}\text { comparison of } \mathrm{CH}_{2} \mathrm{COOH} \text { and } \mathrm{CH}_{3} \mathrm{COOH} \text { BAC- } \\
\text { MP4 calculations [19] }\end{array}$ \\
\hline $\mathrm{CH}_{3} \mathrm{CH}(.) \mathrm{C}(=\mathrm{O}) \mathrm{OR}$ & 96.2 & -2.37 & $\begin{array}{l}\text { values for } \cdot \mathrm{CH}_{2} \mathrm{C}(=\mathrm{O}) \mathrm{OR} \text {, changed by the } \\
\text { difference between } \mathrm{CH}_{3} \mathrm{CH}(.) \mathrm{CHO} \text { and } \cdot \mathrm{CH}_{2} \mathrm{CHO} \\
{[15]}\end{array}$ \\
\hline
\end{tabular}

